\title{
REFERENGE
}

\section{Characterization of Projection Systems for the MPEG-4 Digital Cinema Compression Scheme Evaluation}

\author{
P. A. Boynton" \\ C. Fenimore \\ U. S. DEPARTMENT OF COMMERCE \\ Technology Administration \\ National Institute of Standards \\ and Technology \\ 'Electricity Division \\ ${ }^{\circ}$ Convergent Information Systems Division \\ Gaithersburg, MD 20899-8230
}

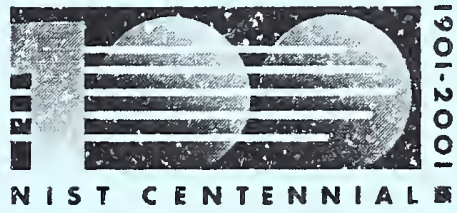

QC 



\title{
Characterization of Projection Systems for the MPEG-4 Digital Cinema Compression Scheme Evaluation
}

\author{
P. A. Boynton" \\ C. Fenimore \\ U. S. DEPARTMENT OF COMMERCE \\ Technology Administration \\ National Institute of Standards \\ and Technology \\ ${ }^{2}$ Electricity Division \\ ${ }^{\circ}$ Convergent Information Systems Division \\ Gaithersburg, MD 20899-8230
}

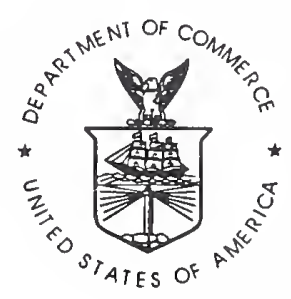

U.S. DEPARTMENT OF COMMERCE Donald L. Evans, Secretary

NATIONAL INSTITUTE OF STANDARDS AND TECHNOLOGY

Dr. Karen H. Brown, Acting Director 



\section{Characterization of Projection Systems for the MPEG-4 Digital Cinema Compression Scheme Evaluation}

\section{Background}

The international standards organization officially titled ISO/IEC/JTC1/SC29/WG11, otherwise known as the Moving Picture Experts Group (MPEG), and the Digital Cinema Ad Hoc Group under MPEG, subjectively assessing various compression algorithms for digital cinema applications. The group designed an experiment involving two digital cinema projectors: a projector using a digital micromirror device (DMD), and a cathode ray tube (CRT) projector. Various trained observers viewed sequential and side-by-side digital cinema clips (one side compressed, the other uncompressed) and rated the quality of the images for each projector. These tests were held at the Entertainment Technology Center (ETC, Hollywood, CA), located in the historic Warner/Pacific Theater on Hollywood Boulevard.

The MPEG Digital Cinema Ad Hoc Group was concerned about whether the system being used (server, interface, projector, screen, viewing room) would block out important details in the assessment of the compression algorithms. NIST was asked to oversee initial measurements made of projectors in order to characterize their performance before the subjective visual testing was begun. THX (a division of LucasFilm, Burbank, CA) made the actual measurements. The responsibilities were broken down as follows:

NIST's role-to oversee the measurement process:

a perform diagnostics to determine instrumentation limitations and provide solutions when possible;

a determine stray-light contributions of the room;

$\checkmark$ determine other factors that might influence the measurements;

」 provide an uncertainty assessment of the measurement process;

a assure that procedures, whenever possible, follow the relevant ANSI and VESA standards;

๖ provide a spreadsheet for data collection and analysis;

a and provide the MPEG Digital Cinema Ad Hoc Group with test patterns.

THX's role:

」 provide measurement equipment;

a perform actual measurements used to evaluate the projectors;

a and provide expertise as needed.

The following describes the results of the projector characterization as reported to the MPEG Digital Cinema Ad Hoc Group in July 2001. 



\section{Characterization of Projection Systems for the MPEG-4 Digital Cinema Compression Scheme Evaluation}

The following data was collected by the THX Division of LucasFilm Ltd., Burbank, CA and by Paul Miller of the Entertainment Technology Center on June 21, 2001. The relative expanded uncertainty of the photometric measurements (with a coverage factor of $k=2$ ) was $12 \%$ in luminance, and \pm 0.005 in 1931 CIE chromaticity coordinates, based on the measurements made by THX. NIST provided technical expertise, measurement diagnostics, test patterns, and uncertainty assessment. NIST also ensured that, where relevant, each measurement followed the appropriate procedures described in the following standards [1]:

ANSI/NAPM IT7.228-1997 Electronic Projection-Fixed Resolution Projectors ANSI/PIMA IT7.227-1998 Electronic Projection-Variable Resolution Projectors VESA Flat Panel Display Measurements Standard Version 2.0 (June 2001)

These measurements characterize the projector system performance on June 21, 2001, at the Warner/Pacific Theater and at the particular settings and configurations on that day. The projection system includes the combined effect of the digital cinema projectors, projection screen, storage system, interfaces, and converters.

The assigned uncertainty does not incorporate shifts due to drift, environmental changes, or readjustment of the projectors. Neither does the uncertainty imply a calibration or certification by NIST. Traceability to NIST can be inferred through the calibration of the measurement equipment provided by THX, but not through any direct comparison with NIST equipment as used at the site.

The measurements and procedures were established through discussions by NIST with Ad Hoc Group members (see Table 3). Some of these measurements and procedures were not performed due to time constraints imposed by the Digital Cinema Ad Hoc Group. In addition to the set-up and diagnostic measurements, the following measurements were made:

Room configuration (geometry of projector, viewer, and screen)

Room conditions (ambient light)

Screen gain

Light output and nonuniformity of white and black

Color temperature and white point

Color chromaticity of primaries and color gamut area

Contrast ratio (checkerboard, sampled, and full-screen)

Gray-scale levels and gamma estimation

Resolution and contrast modulation

Aspect ratio

Patterns were chosen based upon the list of requested measurements and drawn from the set of test patterns developed by Kelley at NIST and Miseli at Sun Microsystems [2]. Descriptions of the patterns described in Table 2 may be found in either the VESA FPDM or the ANSI/PIMA electronic projection standards. Electronic copies of the image files used, in the proper formats, 

are available at http://www.itl.nist.gov/div895/TestPatterns/index.html. Because the two display interfaces and image formats differ, the test patterns were generated in the same formats and stored and displayed using the same system components employed for the subjective viewing tests. Pattern generation was based on specifications in the relevant SMPTE standard [3]. The digital formats for the test patterns and cinema clips for the two projectors are as described in the following table.

Table 1. Image Formats for Projection Systems

\begin{tabular}{|l|l|l|}
\hline \multicolumn{1}{|c|}{ Image Attribute } & \multicolumn{1}{|c|}{ DMD Projection System } & \multicolumn{1}{|c|}{ CRT Projection System } \\
\hline Color-coding components [4] & $\mathrm{R}^{\prime} \mathrm{G}^{\prime} \mathrm{B}^{\prime}$ & $\mathrm{Y}^{\prime} \mathrm{C}^{\prime}{ }_{\mathrm{B}} \mathrm{C}^{\prime}{ }_{\mathrm{R}}$ \\
\hline $\begin{array}{l}\text { Addressable active pixels per } \\
\text { frame }\end{array}$ & $1280 \times 1024$ & $1920 \mathrm{X} 1080$ \\
\hline $\begin{array}{l}\text { Addressable stored pixels per } \\
\text { frame }\end{array}$ & $1920 \times 1080$ & $1920 \times 1080$ \\
\hline Sampling & $4: 4: 4$ & $4: 2: 2$ \\
\hline Bits per sample & 10 & 10 \\
\hline $\begin{array}{l}\text { Full range Rec. 709 code } \\
\text { values }\end{array}$ & {$[64,940]$ for R, G, and B } & $\begin{array}{l}{[64,940] \text { for } \mathrm{Y}} \\
{[64,960] \mathrm{C}_{\mathrm{B}}, \text { and } \mathrm{C}_{\mathrm{R}}}\end{array}$ \\
\hline Image file format & $\mathrm{DPX}[5]$ & $\mathrm{YUV}$ \\
\hline
\end{tabular}

Table 2. Test Patterns

\begin{tabular}{|l|l|}
\hline \multicolumn{1}{|c|}{ DESCRIPTION } \\
\hline SETUP PATTERNS \\
Whed in setup of projector. \\
pattern
\end{tabular}

\footnotetext{
" These code values map to the full range of light output of both projectors. See Ref. 4, p. 12.
} 



\begin{tabular}{|l|l|l|}
\hline FULL SCREEN BLACK \\
Used for black luminance, black nonuniformity, and \\
full-screen contrast measurements.
\end{tabular}





\section{FULL SCREEN GRAY LEVELS}

Used for gray-level luminance and chromaticity measurements, and gamma estimation.

Eight full-screen gray levels were used, assuming 10 bits, with Rec. 709 range [64 - 940]:

Black $(0)=64 / 940$

Level $(1)=189 / 940$

Level $(2)=314 / 940$

Level $(3)=439 / 940$

Level $(4)=564 / 940$

Level $(5)=689 / 940$

Level $(6)=815 / 940$

White $(7)=940 / 940$

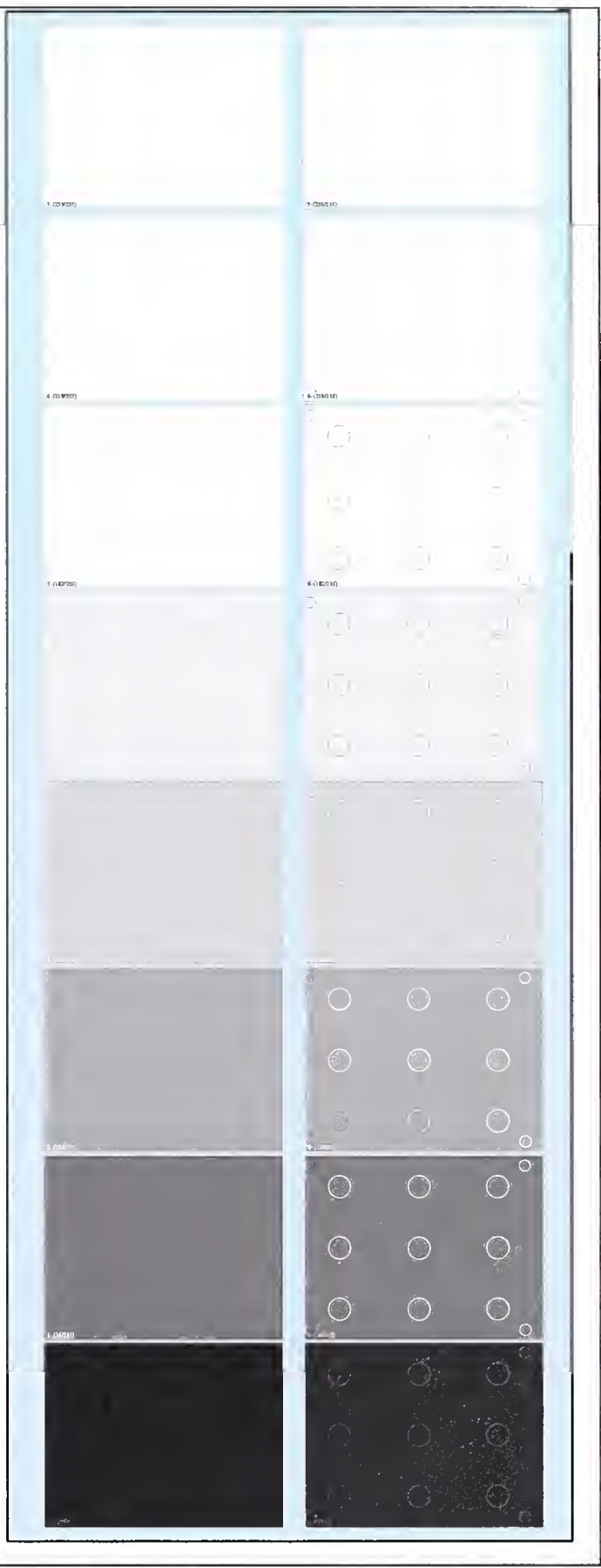



$\mathrm{N} \times$ N HORIZONTAL AND VERTICAL GRILL PATTERNS $(1 \times 1,2 \times 2,3 \times 3,4 \times 4,5 \times 5)$

Used for contrast modulation and resolution measurements. Unless specified otherwise, these patterns will always start with white at left or top. Not all grill patterns are shown here. Patterns shown are magnified for demonstration purposes.

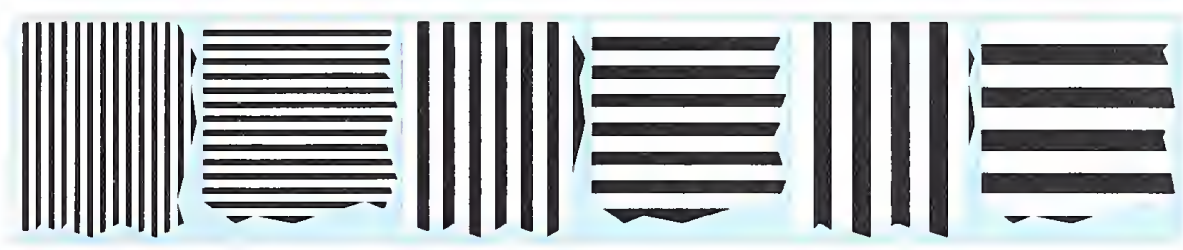

Table 3. Test Procedures

1) Projector setup

a) references

ANSI/NAPM IT7.228 (IEC Draft 61947-1)

1.1 Stipulations

ANSI/NAPM IT7.227 (IEC 61947-2)

1.2 Stipulations

VESA FPDM Ver $2.0(2001)$

301 Setup of Display and Equipment

b) patterns

i) Setup pattern with white background

ii) Setup pattern with $50 \%$ gray background

iii) Setup pattern with black background

iv) Full-screen white field pattern

v) Others as needed

c) procedures

i) Place full-screen white field on screen.

ii) Warm up projector for a minimum of $20 \mathrm{~min}$.

iii) Adjust projector controls to desired settings using setup patterns and other appropriate patterns (performed by projector manufacturers).

iv) At this point, projector controls remain unchanged throughout measurements for the results to be valid. 



\section{2) Evaluate measurement apparatus and room conditions}

a) references [6]

VESA FPDM Ver 2.0 (2001)

301-2 Measurement and Display Conditions

301-3 Display Setup and Subjective Testing

301-4 Measurement Repeatability (Luminance)

A101 Veiling Glare and Lens Flare Errors

A221 Statements of Uncertainty

b) patterns

i) Full-screen white field pattern

ii) Full-screen $4 \times 4$ checkerboard pattern

c) procedures [6]

i) Evaluate alignment error of illuminance meter.

ii) Determine illuminance position error.

iii) Determine repeatability of luminance measurements.

iv) Measure ambient light conditions.

v) Determine veiling glare effects.

vi) Determine other stray-light contributions.

vii) Measure screen gain.

3) Light output, color, and nonuniformity of white and black

a) references

ANSI/NAPM IT7.228 (IEC Draft 61947-1)

4 Light output measurement and specification

4.2 Light uniformity

ANSI/NAPM IT7.227 (IEC 61947-2)

4.1 Light output measurements

5.1 Light output specifications

5.2 Light output uniformity

VESA FPDM Ver 2.0 (2001)

306-1 Sampled Uniformity \& Color of White

306-2 Sampled Uniformity of Black

b) patterns

i) Full-screen white field pattern

ii) Full-screen white field pattern with 13 measurement alignment circles

iii) Full-screen black field pattern

iv) Full-screen black field pattern with 13 measurement alignment circles

c) procedures

i) Place white field pattern onto projection screen. Use the pattern with 13 measurement alignment circles to align LMD at each measurement point, and switch to pattern without circles for measurement. 

ii) Place LMD at design viewing location.

iii) Measure luminance at each measurement location, $L_{i}$, where $i=1, \ldots, 13$.

iv) Calculate the sampled white luminance $L_{w}=\frac{1}{n} \sum_{i=1}^{n=9} L_{i}$ and the sampled chromaticity $x_{w}=\frac{1}{n} \sum_{i=1}^{n=9} x_{i}, y_{w}=\frac{1}{n} \sum_{i=1}^{n=9} y_{i}$ for the $n=9$ positions on the white field (don't use the four corner positions).

v) Calculate the nonuniformity of white, Nonuniformity $=100 \%\left(1-\frac{L_{\min }}{L_{\max }}\right)$, where $L_{\max }$ and $L_{\mathrm{min}}$ are the maximum and minimum measured white luminance, respectively, of the sampled white luminance set: $L_{i}$, where $i=1, \ldots, 13$.

vi) Place black field pattern onto projection screen. Use the pattern with 13 measurement alignment circles to align LMD at each measurement point, and switch to pattern without circles for measurement.

vii) Place $L M D$ at design viewing location.

viii) Measure luminance at each measurement location, $L_{l}$, where $i=1, \ldots, 13$.

ix) Calculate the sampled black luminance $L_{b}=\frac{1}{n} \sum_{i=1}^{n=9} L_{i}$ and the sampled chromaticity $x_{b}=\frac{1}{n} \sum_{i=1}^{n=9} x_{i}, y_{b}=\frac{1}{n} \sum_{i=1}^{n=9} y_{i}$ for the $n=9$ positions on the black field (don't use the four corner positions).

x) Calculate the nonuniformity of black, Nonuniformity $=100 \%\left(1-\frac{L_{\min }}{L_{\max }}\right)$, where $L_{\max }$ and $L_{\min }$ are the maximum and minimum measured black luminance, respectively, of the sampled black luminance set: $L_{i}$, where $i=1, \ldots, 13$.

xi) Report luminance, nonuniformity, and chromaticity of white and black.

\section{4) Color temperature and white point}

a) references:

ANSI/NAPM IT7.228 (IEC Draft 61947-1)

5.5 Color measurements

ANSI/NAPM IT7.227 (IEC 61947-2)

6.6 Color measurements

VESA FPDM Ver 2.0 (2001)

302-1 Luminance and Color of Full-Screen White

b) patterns:

i) Full-screen white field

ii) Full-screen white field with 13 measurement alignment circles

c) procedures:

i) Place white field pattern onto projection screen. Use the pattern with 13 measurement alignment circles to align LMD at each measurement point, and switch to pattern without circles for measurement. 

ii) Direct LMD at center screen position from design viewing location.

iii) Measure the white-point chromaticity $\left(x_{\mathrm{W}}, y_{\mathrm{W}}\right)$ and the CCT.

iv) Use formulas 5(3.3.4) and 6(3.3.4) in Wyszecki and Stiles, Color Science (pp. 145146 , second Ed., Wiley, 1982) to compute the point $\left(x_{\mathrm{d}}, y_{\mathrm{d}}\right)$ on the daylight locus that is associated with CCT $T_{\mathrm{B}}$. First, define $\mathrm{g}=1000 / T_{\mathrm{B}}$

If $T_{\mathrm{B}}<7000$, then $x_{\mathrm{d}}=-4.6070 \mathrm{~g}^{3}+2.9678 \mathrm{~g}^{2}+0.09911 \mathrm{~g}+0.244063$.

If $T_{\mathrm{B}}>7000$, then $x_{\mathrm{d}}=-2.0064 \mathrm{~g}^{3}+1.9018 \mathrm{~g}^{2}+0.24748 \mathrm{~g}+0.237040$.

In either case, $y_{\mathrm{d}}=3.000 x_{\mathrm{d}}^{2}+2.870 x_{\mathrm{d}}-0.275$.

v) Convert $\left(x_{\mathrm{W}}, y_{\mathrm{W}}\right)$ and $\left(x_{\mathrm{d}}, y_{\mathrm{d}}\right)$ to $u^{\prime} v^{\prime}$ coordinates:

$$
\begin{aligned}
& \left(u_{\mathrm{W}}^{\prime}, v^{\prime}{ }_{\mathrm{W}}\right)=\left(4 x_{\mathrm{W}}, 9 y_{\mathrm{W}}\right) /\left(3+12 y_{\mathrm{W}}-2 x_{\mathrm{W}}\right) \\
& \left(u_{\mathrm{d}}^{\prime}, v_{\mathrm{d}}^{\prime}\right)=\left(4 x_{\mathrm{d}}, 9 y_{\mathrm{d}}\right) /\left(3+12 y_{\mathrm{d}}-2 x_{\mathrm{d}}\right)
\end{aligned}
$$

vi) Evaluate $\Delta u^{\prime} v^{\prime}$ between $\left(u_{\mathrm{W}}^{\prime}, v_{\mathrm{W}}^{\prime}\right)$ and $\left(u_{\mathrm{d}}^{\prime}, v_{\mathrm{d}}^{\prime}\right)$ :

$$
\Delta u^{\prime} v^{\prime}=\sqrt{\left(u_{W}^{\prime}-u_{d}^{\prime}\right)^{2}+\left(v_{W}^{\prime}-v_{d}^{\prime}\right)^{2}}
$$

vii) Report CCT, chromaticity of white point, and color difference.

\section{5) Color chromaticity and gamut area}

a) references:

ANSI/NAPM IT7.228 (IEC Draft 61947-1)

5.51 Color chromatically

5.52 Color uniformity

ANSI/NAPM IT7.227 (IEC 61947-2)

6.6.1 Color chromaticity

6.6.2 Color uniformity

VESA FPDM Ver 2.0 (2001)

302-4 Gamut and Color of Full Screen

302-4A Gamut-Area Metric

b) patterns:

i) Full-screen red field

ii) Full-screen red field with 13 measurement alignment circles

iii) Full-screen green field

iv) Full-screen green field with 13 measurement alignment circles

v) Full-screen blue field

vi) Full-screen blue field with 13 measurement alignment circles

c) procedures:

i) For each full-screen primary (RGB), place the appropriate pattern onto projection screen. Use the pattern with 13 measurement alignment circles to align LMD at the measurement point, and switch to pattern without circles for measurement.

ii) Measure luminance and chromaticity at center screen for all of the full-screen primaries. 

iii) Calculate projector gamut as a percentage of color space using center-screen values: $A=256.9\left|\left(u_{r}^{\prime}-u_{b}^{\prime}\right)\left(v_{g}^{\prime}-v_{b}^{\prime}\right)-\left(u_{g}^{\prime}-u_{b}^{\prime}\right)\left(v_{r}^{\prime}-v_{b}^{\prime}\right)\right|$.

iv) Report color gamut area, and for each primary color, report center screen luminance and chromaticity.

\section{6) Contrast ratio}

a) references:

ANSI/NAPM IT7.228 (IEC Draft 61947-1)

4.3 Contrast ratio

ANSI/NAPM IT7.227 (IEC 61947-2)

5.3 Contrast ratio

VESA FPDM Ver 2.0 (2001)

302-3 Darkroom Contrast Ratio of Full Screen

306-3 Sampled Uniformity of Contrast Ratio

304-9 Checkerboard Luminance and Contrast $(\mathrm{n} \times \mathrm{m})$

b) patterns :

i) Full-screen white field

ii) Full-screen white field with 13 measurement alignment circles

iii) Full-screen black field

iv) Full-screen black field with 13 measurement alignment circles

v) Full-screen $4 \times 4$ checkerboard pattern

vi) Full-screen $4 \times 4$ checkerboard pattern with I 6 measurement alignment circles

c) procedures:

i) Using the center-screen white and center-screen black luminance measurements, calculate full-screen contrast ratio $C=\frac{L_{w}}{L_{b}}$.

ii) Using the sampled white and sampled black luminance measurements, calculate average sampled contrast ratio $C_{\text {Uave }}=\frac{1}{n} \sum_{i=1}^{n=9} \frac{L_{w}}{L_{b}}$ where $\mathrm{i}=1, \ldots, 9$ sampled points on the screen.

iii) Calculate nonuniformity of contrast ratio $=100 \%\left(1-\frac{C_{\min }}{C_{\max }}\right)$, where $C_{\max }$ and $\mathrm{C}_{\min }$ are the maximum and minimum contrast, respectively, of the sampled contrast set: $C_{i}$, where $i=1, \ldots, \mathrm{I} 3$.

iv) Place $4 \times 4$ checkerboard projection screen. Use the pattern with 16 measurement alignment circles to align LMD at each measurement point, and switch to pattern without circles for measurement.

v) Direct LMD at center screen position from design viewing location.

vi) Measure the screen luminance at each of the 16 points, compensating for veiling glare as necessary. 

vii) Calculate the average checkerboard contrast $C_{\text {Cave }}=\frac{1}{n} \sum_{i=1}^{n} \frac{L_{w}}{L_{b}}$, where $\mathrm{n}=8$ (number of black and white checkerboard pairs).

viii) Report the full screen contrast, average sampled contrast, checkerboard (ANSI) contrast, and contrast nonuniformity.

\section{7) Gray Scale}

a) references:

VESA FPDM Ver 2.0 (2001)

302-5 Gray Scale of Full Screen

302-5a Determination of "Gamma"

b) patterns (full-screen gray levels w/ center measurement alignment circles with Rec.709 range [64-940]):

i) Full-screen black $(0)=64$

ii) Full-screen black $(0)=64$ with measurement alignment circles

iii) Full-screen gray level $(1)=189$

iv) Full-screen gray level (1) $=189$ gray with measurement alignment circles

v) Full-screen level gray $(2)=314$

vi) Full-screen level gray $(2)=314$ with measurement alignment circles

vii) Full-screen level gray (3) $=439$

viii) Full-screen level gray $(3)=439$ with measurement alignment circles

ix) Full-screen level gray (4) $=564$

x) Full-screen level gray $(4)=564$ with measurement alignment circles

xi) Full-screen level gray $(5)=689$

xii) Full-screen level gray $(5)=689$ gray with measurement alignment circles

xiii) Full-screen level gray $(6)=815$

xiv) Full-screen level gray $(6)=815$ gray with measurement alignment circles

xv) Full-screen white $(7)=940$

xvi) Full-screen white (7) $=940$ with measurement alignment circles

c) procedures:

i) For each full-screen gray level, place the appropriate pattern onto projection screen. Use the pattern with 13 measurement alignment circles to align LMD at the measurement point, and switch to pattern without circles for measurement.

ii) Direct the LMD at center screen from the design viewing location.

iii) Measure center screen luminance $L$ and chromaticity $(x, y)$ for the full-screen gray scale levels.

iv) Plot the electro-optic transfer function and estimate gamma. Because the full dynamic gray scale has black level code of 64 , the gray scale codes are adjusted by subtracting 64 for the gamma estimate. Determine the gamma by fitting a curve to the luminance data using the model: $L=a V^{\gamma}+L_{b}$, or in terms of $\operatorname{logs}, \log \left(L-L_{b}\right)=\gamma \log (V)+\log (a)$, where $a$ and $\gamma$ relate the signal level $V$ to the luminance $L$ and $L_{\mathrm{b}}$ is the black-level luminance. 

v) Report gray scale luminances and chromaticity, gamma estimate, and show plot of electro-optic transfer function.

\section{8) Resolution}

a) references:

ANSI/NAPM IT7.228 (IEC Draft 61947-1)

4.4 Small area contrast ratio for alternating black and white pixels

5.1 Displayable format (ANSI Resolution)

ANSI/NAPM IT7.227 (IEC 61947-2)

6.1 Variable resolution measurement and specification

Annex G Alternative method for measuring resolution using the NIDL grille contrast method

VESA FPDM Ver 2.0 (2001)

303-2 N $\times \mathrm{N}$ Grille Luminance and Contrast

303-7 Resolution from Contrast Modulation

b) patterns (black on white):

i) $1 \times 1$ vertical grill ( 1 column on, 1 column off)

ii) $2 \times 2$ vertical grill

iii) $3 \times 3$ vertical grill

iv) $4 \times 4$ vertical grill

v) $5 \times 5$ vertical grill

vi) $1 \times 1$ horizontal grill ( 1 row on, 1 row off)

vii) $2 \times 2$ horizontal grill

viii) $3 \times 3$ horizontal grill

ix) $4 \times 4$ horizontal grill

x) $4 \times 4$ horizontal grill

c) procedures:

i) Place the appropriate pattern onto projection screen.

ii) Direct the LMD at center screen from the design viewing position.

iii) Measure the black illuminance $E_{\mathrm{k}}$ and white illuminance $E_{\mathrm{w}}$ for several grilles and take the average for black and white.

iv) Calculate the contrast modulation $C_{m}=\frac{E_{\text {peak }}-E_{\text {valley }}}{E_{w}+E_{k}}$ for each pattern, where $E_{\mathrm{w}}$ and $E_{\mathrm{k}}$ are the average white and black checkerboard illuminances, respectively.

v) Calculate $n_{\mathrm{r}}$, the calculated grille line width (in pixels) for which $C_{\mathrm{m}}$ is estimated to be equal to the contrast modulation threshold $C_{\mathrm{T}}=33 \%(\mathrm{ANSI})$ or $C_{\mathrm{T}}=25 \%(\mathrm{VESA})$ : $n_{r}=n+\frac{C_{T}-C_{m}(n)}{C_{m}(n+1)-C_{m}(n)} \quad$ for $C_{m}(n)<C_{T}<C_{m}(n+1)$.

vi) Calculate the resolution (in number of resolvable pixels) $=\frac{\# \text { of addressable lines }}{n_{r}}$ for both horizontal and vertical directions. 

vii) Report addressability, resolution, and show contrast modulation plots.

\section{9) Aspect Ratio}

a) references:

ANSI/NAPM IT7.228 (IEC Draft 61947-1)

\subsection{Aspect Ratio}

VESA FPDM Ver 2.0 (2001)

501-2 Aspect Ratio

b) pattern:

i) Distortion pattern

c) procedures:

i) Place distortion pattern on screen.

ii) Measure horizontal distance across center, $\mathrm{H}$.

iii) Measure vertical distance across center, $\mathrm{V}$.

iv) Calculate aspect ratio $\alpha=\frac{H}{V}$.

v) Convert decimal aspect ratio to the nearest integer aspect ratio. 

Table 4. PROJECTION SYSTEM ${ }^{\dagger}$ CHARACTERISTICS FOR MPEG DIGITAL CINEMA TESTING

DATE: June 21, 2001

LOCATION: Warner/Pacific Theater, Hollywood, CA

MEASUREMENTS TAKEN BY: Simon Allen, THX; Paul Miller, ETC

OBSERVERS Paul Boynton, Electronics and Electrical Engineering Laboratory, NIST

Charles Fenimore, Information Technology Laboratory, NIST

\begin{tabular}{|c|c|c|}
\hline GEOMETRY & DMD Projection System & CRT Projection System \\
\hline \begin{tabular}{l|l} 
& Projeetor distance from eenter sereen \\
\end{tabular} & $14 \mathrm{~m}$ & $9 \mathrm{~m}$ \\
\hline Design viewing distanee from eenter sereen & $5 \mathrm{~m}$ & $5 \mathrm{~m}$ \\
\hline Angle of ineidence & $0.4^{\circ}$ & $10^{\circ}$ \\
\hline Angle of refleetanee & $25^{\circ}$ & $25^{\circ}$ \\
\hline AMBIENT LIGHT (center screen, projector off) & $0.02 \mathrm{~lx}$ & $0.02 \mathrm{~lx}$ \\
\hline SCREEN GAIN (from design viewing location) & 1.0 & 1.0 \\
\hline \multicolumn{3}{|l|}{ LUMINANCE AND UNIFORMITY } \\
\hline \begin{tabular}{l|l} 
& Sampled luminanee of white \\
\end{tabular} & $43 \mathrm{ed} / \mathrm{m}^{2}$ & $4.6 \mathrm{ed} / \mathrm{m}^{2}$ \\
\hline Sampled luminanee of blaek & $0.05 \mathrm{ed} / \mathrm{m}^{2}$ & $0.01 \mathrm{ed} / \mathrm{m}^{2}$ \\
\hline Nonuniformity of white & $32 \%$ & $59 \%$ \\
\hline Nonuniformity of blaek & $54 \%$ & $5.9 \%$ \\
\hline Sampled eolor temperature & $5837 \mathrm{~K}$ & $6508 \mathrm{~K}$ \\
\hline Sampled white point $(\mathrm{x}, \mathrm{y})$ & $(0.324,0.362)$ & $(0.313,0.314)$ \\
\hline \multicolumn{3}{|l|}{$\begin{array}{l}\text { LUMINANCE AND CHROMATICITY OF } \\
\text { PRIMARIES }\end{array}$} \\
\hline \begin{tabular}{l|l} 
Luminanee of red \\
\end{tabular} & $7.0 \mathrm{ed} / \mathrm{m}^{2}$ & $2.7 \mathrm{ed} / \mathrm{m}^{2}$ \\
\hline Chromatieity of red $(x, y)$ & $(0.660,0.305)$ & $(0.659,0.338)$ \\
\hline Luminance of green & $18 \mathrm{ed} / \mathrm{m}^{2}$ & $4.7 \mathrm{ed} / \mathrm{m}^{2}$ \\
\hline Chromatieity of green $(x, y)$ & $(0.251,0.665)$ & $(0.325,0.590)$ \\
\hline Luminance of blue & $3.1 \mathrm{ed} / \mathrm{m}^{2}$ & $0.6 \mathrm{ed} / \mathrm{m}^{2}$ \\
\hline Chromaticity of blue $(x, y)$ & $(0.138,0.070)$ & $(0.146,0.064)$ \\
\hline Color gamut area & $39.5 \%$ & $32.6 \%$ \\
\hline \multicolumn{3}{|l|}{ CONTRAST } \\
\hline \begin{tabular}{l|l} 
Full screen contrast ratio at eenter \\
\end{tabular} & $880: 1$ & $940: 1$ \\
\hline Sampled eontrast ratio (9-point) & 930:1 & $690: 1$ \\
\hline Contrast nonuniformity (13-point) & $56 \%$ & $40 \%$ \\
\hline Cheekerboard eontrast $(4 \times 4)$ & $140: 1$ & $76: 1$ \\
\hline
\end{tabular}

${ }^{\dagger}$ Includes projector, screen, storage system, interfaces, and converters for luminance measurements. Illuminance measurements (including the resolution measurements) do not include the screen in the system.

${ }^{\ddagger}$ The relative expanded uncertainty for the photometric measurements is estimated to be $\pm 12 \%$ for a coverage factor of $k=2$, and for the colorimetric measurements, \pm 0.005 in CIE 1931 chromaticity coordinates $(\mathrm{x}, \mathrm{y})$. 



\begin{tabular}{|l|l|l|l|}
\hline \multicolumn{2}{|l|}{ RESOLUTION } & DMD Projection System & CRT Projection System \\
\hline & Contrast modulation threshold criteria & $25 \%$ & $25 \%$ \\
\hline & Addressability—horizontal & 1280 & 1920 \\
\hline & Addressability_vertical & 1024 & 1080 \\
\hline & \# Of resolvable pixels—horizontal & 1280 & 1528 \\
\hline & \# Of resolvable pixels_vertical & 1024 & 794 \\
\hline & & & \\
\hline ASPECT RATIO & & \\
\hline & Decimal & 1.25 & 1.79 \\
\hline & Integer & $5: 4$ & $16: 9$ \\
\hline
\end{tabular}

\begin{tabular}{|c|c|c|c|c|c|c|}
\hline GRAY SCALE & \multicolumn{3}{|c|}{ DMD Projection System } & \multicolumn{3}{|c|}{ CRT Projection System } \\
\hline Gamma & 2.53 & & & 2.18 & & \\
\hline & & & & & & \\
\hline & luminance & $\mathrm{x}$ & $y$ & luminance & $\mathrm{x}$ & $y$ \\
\hline Gray Scale Value $=940$ & 44 & 0.324 & 0.363 & 6.4 & 0.318 & 0.315 \\
\hline Gray Scale Value $=815$ & 29 & 0.324 & 0.363 & 4.9 & 0.322 & 0.319 \\
\hline Gray Scale Value $=689$ & 18 & 0.324 & 0.363 & 3.5 & 0.325 & 0.320 \\
\hline Gray Scale Value $=564$ & 10 & 0.324 & 0.364 & 2.2 & 0.329 & 0.317 \\
\hline Gray Scale Value $=439$ & 4.9 & 0.324 & 0.363 & 1.3 & 0.326 & 0.309 \\
\hline Gray Scale Value $=314$ & 1.7 & 0.325 & 0.363 & 0.53 & 0.319 & 0.301 \\
\hline Gray Scale Value $=189$ & 0.33 & 0.330 & 0.363 & 0.087 & 0.326 & 0.317 \\
\hline Gray Scale Value $=64$ & 0.053 & 0.368 & 0.365 & 0.0084 & low si & \\
\hline
\end{tabular}

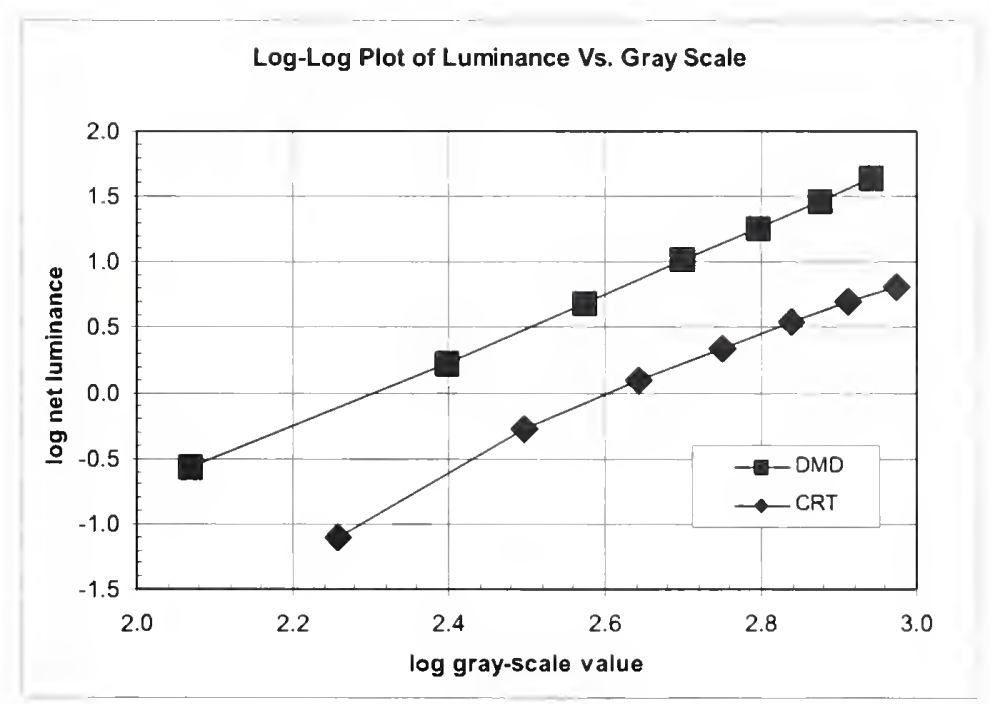




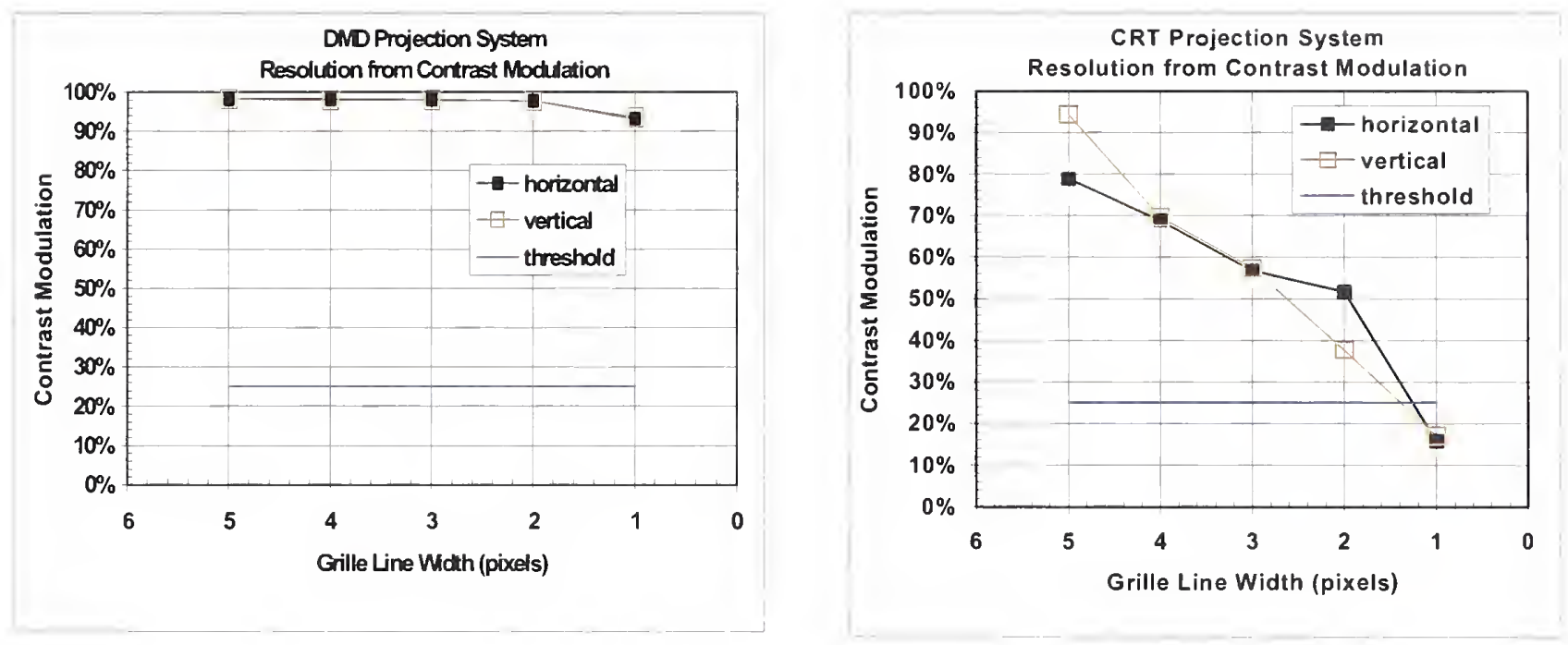

\section{ACKNOWLEDGEMENTS}

The authors would like to acknowledge the contributions of Simon Allen of THX Division of LucasFilm Ltd., who performed most of these measurements; Paul Miller of the Entertainment Technology Center, who assisted in the measurements; Alexei Nikolaev of NIST, who assisted in the generation of the test patterns; and Ed Kelley of NIST, who provided valuable input on the measurement procedures.

\section{REFERENCES}

1. The international versions of the ANSI standards, IEC 61947-1 Ed. 1.0 and IEC 61947-2 Ed. 1.0, are as of the date of this report still in draft form.

2. E. F. Kelley and J. V. Miseli, "Setup Patterns for Display Measurements-Version 1.0," NISTIR 6758 (June 2001)

3. SMPTE Standard 274M: 1920 X 1080 Scanning and Analog and Parallel Digital Interfaces for Multiple Picture Rates [1998.]

4. ITU-R BT.709-4 Parameter Values for the HDTV Standards for Production and International Programme Exchange [2000].

5. SMPTE 268M-1994 File Format for Digital Moving-Picture Exchange.

6. Some of these procedures will be outlined in more detail in a NIST Interagency Report (IR), "Projection Display Metrology Procedures, Tools, and Diagnostics," to be published. 


